\title{
Directed Formation of Motivation and Professional Orientation of Students toward Professions in the Field of Preventive Medicine
}

\author{
https://doi.org/10.3991/ijet.v15i14.13963 \\ Natalya Biryukova ${ }^{(凶)}$, Natalia M. Molodozhnikova \\ I.M. Sechenov First Moscow State Medical University, Moscow, Russia \\ N.V.Biryukova@mail.ru
}

\begin{abstract}
The article discusses the directed formation of motivation and professional orientation in students towards professions in the field of preventive medicine, such as the professions of an epidemiologist and a general hygiene doctor. The method that we have developed for the directed formation of cognitive interest in a particular profession makes it possible to create a guided vocational guidance for high school students depending on the social order. The complexity of the problem lies in the fact that the target of our study is students of specialized medical classes, who have already developed a cognitive interest and professional orientation toward the future specialty of a medical practitioner, while neither epidemiologist nor general hygienist is involved in treating patients. The specially carried out work on the directed formation of cognitive interest and professional orientation to the profession of a doctor of epidemiologist, general hygiene doctor solved the problem.
\end{abstract}

Keywords-Motivation, pre-vocational education, directed formation of interest, natural science

\section{Introduction}

Medical education consists of several stages - pre-university, university and postgraduate education. Any path is determined by its beginning. The directed formation of interest to medical professions among senior students solves the problem of adequate professional orientation towards it [1] [2]. The biomedical classes of Sechenov University successfully carry out the process of developing such orientation. In the future, we will dwell on the development of interest in the medical profession. To do this, firstly, we need to find out the level of social development of high school students, the initial level of their needs, as well as of their cognitive and motivational sphere and their traditional ways of orientation in choosing a particular profession.

The social development of high school students is influenced by the need for personal self-determination and planning of their own future, where the choice of a future profession and the construction of a personal life plan take the central place. Achieving the specialty, to the development of which the aspirations of high school students 
are directed, is a goal to which they subordinate their needs and focus their dreams. At this age, teenagers stand at the start of their independent lives. These are people facing the future. During this period their worldview, moral and ethical values, plans for the future are formed, among which the choice of the future profession is the core. However, the traditional analysis of this choice shows that it causes considerable difficulties for young people and is often associated with the fact that students are disappointed in the decision made during the professional training. The reason for this is young people's wrong choice of their profession. If the choice is not conscious and supported by the applicants' sufficient knowledge of their future professions' features, later they become certain that the chosen profession does not correspond to their initial idea of it, which leads to disappointment and other negative states.

The main reason for this state of affairs is the lack of directed vocational guidance, insufficient informing of high school students about existing professions and the inability to conduct vocational guidance training on their own. Regarding that, I. S. Cohn writes [6]: "The choice of a profession implies that students have two kinds of information: about the world of professions in general and of the possibilities and requirements of each of them; about themselves, their abilities and interests. Either of that information is not enough for high school students. As the famous sociologist, V.N. Shubkin, writes, summarizing the results of many years of research, at the age of 17 the attitude to the world of professions is based on borrowed experience - the information received from parents, acquaintances and peers, from books, movies and television programs. This experience is usually abstract, not experienced, not hard-won”. Describing the results of this traditional orientation toward the choice of a future profession, it should be noted that in the process of studying at a university in a chosen specialty, at least a third of the students surveyed give an uncertain or negative answer to the question of the correct choice of a profession. The share of positive answers in some universities was less than half. Moreover, the number of students surveyed who are dissatisfied with their choice of specialty is not decreasing but growing among senior undergraduates [6].

High school students making a traditional choice of a medical specialty face this problem as well. As studies have shown, there is always a big competition when entering medical universities due to the fact that the medical profession has a high public rating and prestige, [3]. Despite this, there are many difficulties in generating interest in medical specialties in senior school students. The main problem is that medical classes' students and first-year students cannot independently objectively realize the quintessence of future activities involved in their future specialty, thereby distorting their life plans, moving along a path that does not correspond to their real needs and interests. Work in a particular profession is often perceived from the standpoint of its social significance and attractiveness, in isolation from the essence of the content and practical possibilities of its implementation. The figurative name of such a perception of a doctor's specialty as "the halo of a white coat" is often found in the literature. As the analysis of the literature and our research shows, the main preference that most medical school graduates are guided by is often not directly related to realizing the implications of their future activities, personal qualities, and the ability to fulfill the professional requirements. Students of the first two years of medical univer- 
sities also do not have an objective answer to the question: "What is the profession of a doctor?" since they actually are not yet exposed to clinical disciplines. This is because there is no objective system and criteria for the differential identification of applicants with different professional interests and personal qualities necessary for a particular area of training implemented in medical schools at present. Late-coming understanding of the lack of deep interest in future professional activities makes learning a joyless and very difficult job. Many students are unable to deal with them and leave, but more often young people are expelled from the university. As it was noted by I. S. Suk, “...several percent of the total number of students drop out from the medical institutes of the country annually. But life shows that this screening is not enough: there are still many people superfluous in medicine among medical students" [7]. The number of expelled students should also include those who enter a medical university with interests that are inappropriate for the future profession and who are oriented, first of all, to its social significance.

Sechenov University implements an innovative and integrative model of preuniversity education, in which the set goals and objectives are achieved in a holistic (systemic) aspect [8]. Much attention in the implementation of this model is paid to the formation of internal motivation for the upcoming activities of a doctor and professional orientation to the profession.

\section{Research Methods}

This technique is based on the analysis and systematization of previously conducted studies [3] [4]. It has been established that cognitive interest or motivation for medical work arises in the complex process of search and value-orientation activities (the formation of interest in traditional education takes from several months to 8-10 years), consisting of:

a) The formation of ideas about future professional activity, expectations of its development, the availability of a resource for the realization of creative abilities in it and professional growth;

b) The analysis of the type of professional activity from the position of life value orientations, spiritual requests, etc.;

c) Building an objective perspective of achieving the set goal, taking into account the possibilities of realizing the person's aspirations and needs.

Both a cognitive activity, characterized by an objective understanding of the content and specificity of future professional activity and value-orientated activity take part in the formation of motivation. These are the activities aimed at understanding the social significance of the chosen profession, at planning life prospects and ways to achieve goals.

Before conducting a meaningful description of the method of the directed formation of motivation for the profession of a doctor, we are going to focus on the content of value-oriented, biased activity, which has great importance in the directed 
formation of motivation to professional activity and studying during the period of profile preparation.

The value-oriented activity, at certain age periods, is the leading one that determines the mental neoplasm of this stage. For example, according to D. B. Elkonin, in adolescence the leading activity is communication with people of the same age, a personal, deep interaction and development of various personal norms and rules of social behavior in the society [9][10]. In the course of this activity, an awareness of one's own personality is formed, which plays a significant role at this age, since life self-determination and the construction of personal plans take place in during this period. The central issue of those plans is the choice of a future specialty [10].

Moral awareness also arises in the course of value-orientation activities, which allows a teenager manifests himself as a free, intelligent and self-conscious being [11]. It forms the worldview, ethical, aesthetic and legal culture. I.V. Bestuzhev-Lada notes in his works that the formation of this culture, as a rule, takes place spontaneously and does not achieve the desired result (12). The author of this study raises the question of the need to form personality characteristics in school age. In the process of this activity, there is an interest in choosing a certain area of future professional activity, based on which the choice of specialty is determined. Due to the fact that a traditional education does not pay enough attention to this activity, various difficulties arise in the formation of the required personal qualities. This also applies to professional selfdetermination.

Implementing the directed formation of personal (first of all, moral and ethical) qualities, including internal motivation to the profession of a doctor, we must manage the value-orientated, meaning-forming activity.

The directed formation of internal motivation among students is much more complicated than the management of cognitive activity and the assimilation of educational material by them. In this case, a theoretical description of the professional and personal qualities required by a particular medical specialty is not enough.

Students need not only to realize, but also to accept the need for these qualities, which contributes to the emergence of an internal belief in the correctness of the choice. This is the main issue in the development of a true interest in the profession. The process of internal acceptance or, vice versa, non-acceptance takes place during a special independent activity. We have named such an activity value-orientated, semantic-forming, emotional activity for solving vital tasks. The regulation of valueoriented activities implies both knowledge of the intellectual level of a high school student and an understanding of the initial state of his motivation needs.

We can form personal qualities of young people in the necessary direction only in the presence of students' aspiration and desire. In this logic of axiology, people and their value characteristics act as subjects and predicates, as opposed to proofs in formal logic, where things and their properties act in this quality. In the directed conviction or persuasion of a person, one of the judgments must include an important characteristic that a given person has - even if this characteristic does not correspond to the objective social requirements presented by the society to the person (for example, the desire of a young person to take a dominant position in a class or group through academic achievement). 
The conclusions include the necessary value characteristic, which must be understood and internally accepted and, thus, take an appropriate place in the already existing hierarchy of values of a senior pupil's personality. In the course of logical thinking and presenting evidence, and from the point of view of the existing system of value guidelines for high school students, their objective inconsistency to the society's requirements to a medical profession is revealed. At the same time, the study shows that the desire for self-affirmation and self-expression can be obtained only by deep mastery of the necessary professional skills. Due to this, significant changes take place in the motivation needs sphere of high school students and in the hierarchy of their value orientations, corresponding to the objective requirements for a doctor's training.

An important task in the directed formation of a relevant interest in the profession of a doctor is to bring the existing system of needs and values of a young man in line with the hierarchy of social values of the profession, by managing his value-oriented activities, and to transform them into substantial characteristics necessary for the profession. Thus, the management of the value-orientation activities of high school students should be based on the knowledge of the initial level of their motivation needs sphere, on the one hand, as well as on the knowledge of the substantial requirements that society sets for the medical profession and of their value characteristics, on the other. The importance and role of the doctor in the society determines the high rating of this profession, as well as the requirements for the specialist's moral, ethical and aesthetic qualities: in the view of the society, the doctor should be characterized by empathy, responsiveness, self-restraint, restraint, nobility, honesty, responsibility, humanity, warmth, feeling beautiful, goodwill, duty, etc.

The structure of students' needs, desires, aspirations and motives is formed already at school age. The characteristics of the initial level of motivation needs sphere of adolescence are given in the works of L.I. Bozhovich [5], I.S. Kona [6], I.I. Krylova [13] and others.

The main that a teenager faces is to determine their place in life. First of all, this is a decision on choosing a future profession, planning their own path in life, understanding the meaning of their life.

As a rule, when choosing their career path, a person follows the desire to choose a profession, which gives opportunities for great prospects and which is creative in nature. If future work makes it possible to get a high social position, such a profession becomes more preferable. When a young person has determined their career path the future profession acts as a crucial goal, which directs all their desires, dreams, needs and aspirations. In the studies of E.I. Volkova [14] first-year students showed the following determining motives for admission to a medical university and choosing a medical specialty (the list goes in descending order of importance): a desire to treat people; a desire to alleviate the suffering of patients, family traditions and the prestige of the profession; and completes the list of desire to solve medical scientific problems.

According to a Levada Center survey conducted among Russians over the past three years to find out which profession they would like their children or grandchildren to choose, the medical profession has been the most popular, leaving behind lawyers, financiers and businessmen. Therefore, the competition in medical universi- 
ties is one of the highest among universities. Consequently, the problem is not in the number of applicants entering a medical university, but in their quality. Regrettably, such applicants who have a deep steady interest in mastering this profession, an adequate idea of the nature of this work and understanding how to achieve their goals, are not the vast majority in the total number of students entering medical universities yet. In order to raise the quality of applicants it is useful to propaedeutically inform senior school students about the historical development of medicine, giving impressive examples, such as description of famous scientists' achievements. Using clear examples, we can demonstrate that achieving high social status is possible only through constant self-development and acquisition of professional skills and abilities. To achieve this, students must build the trajectory of their professional activities, conduct self-analysis of the prospects for personal growth. Only by realizing the true essence of the doctor's work, the importance of its conscientious implementation for maintaining the health of the community, can a young man become aware of the value of this type of activity and his future social status. It is necessary to show that there is only one true path to self-improvement, self-assertion and the achievement of the desired future the development of this type of professional activity. In the course of this work, it is necessary to show that for the professional performance of their functions, the doctor needs both good professional training and moral, ethical and aesthetic qualities: empathy, self-restraint, modesty, goodwill, disinterestedness, responsiveness, honesty, humanity, responsibility, duty, etc. Direct introduction of high school students to the working conditions of clinicians is of great importance. To provide students of Sechenov University biomedical classes with the opportunity to get acquainted with the real working conditions of doctors, a special course "Step into medicine" was developed. As the authors of the work [15] indicate, this course includes excursion and introductory programmes that include adolescents visiting the clinical facilities of Sechenov University. The students of specialized biomedical classes are actively taking part in such events as visiting The Museum of the History of Medicine, the Botanical Garden, and the relevant departments of Sechenov University. A lot of excursions, lectures, seminars and master classes are regularly organized in the buildings of Sechenov University [16]. All this provides students of biomedical classes with an opportunity to dive into real working conditions of doctors and to realize the requirements of the society towards them. During training in biomedical classes, students should build a reasonable life perspective for achieving their goals and perceive the study of academic disciplines as a necessary stage in mastering the medical profession, and the upcoming residency as a way to improve professional experience. The medicine today faces are a lot of urgent scientific problems, the solution of which could significantly improve the quality of medical care for patients. One of the objectives of the course is to educate young people aimed at solving these problems in science and striving to enter the university and to subsequently carry out scientific work at the doctoral level. 


\section{Research Results}

Creating the above-described method of formation of directed motivation and professional orientation towards the profession of a doctor, we set a very difficult task to interest the part of students in the biomedical classes of Sechenov University in preventive medicine, to organize their training according to a special program, and thereby fulfill the social order of the Moscow health care.

It should be noted that we decided to generate interest in preventive medicine in students of biomedical classes, who initially preferred the profession of a medical practitioner, and demonstrated significant interest in this direction. It was necessary to reorient some of the tenth and eleventh graders to the specialty of an epidemiologist or hygienist. A significant difference between the work of the medical practitioner and the work of the epidemiologist or hygienist is that the first one deals with patients, while the latter do not directly treat patients. Two groups of students of biomedical classes were taken for the study - one group of the tenth graders (30 people), the other group was formed out of students of the eleventh grade (30 people).

Our study consisted of two stages.

The first stage of the study for these groups was getting familiar with new specialities.

At the second stage, according to the method described above, a directed formation of motivation and professional orientation toward preventive medicine was carried out in the same groups.

At the first stage of the study, the students of the selected groups were announced that Moscow Health Care Department had placed an order for the training of doctors in epidemiology and hygiene, and therefore two groups of students from biomedical classes would be created, which would be prepared according to a special program in preventive medicine. The participants in the groups were told about the content of the work of specialists in epidemiology and hygiene, in accordance with the qualification characteristics of these specialties. Then the students were invited to sign up for the training in this new direction. In the group of the $11^{\text {th }}$ grade, there were no people willing to devote themselves to a new specialty. In the group of $10^{\text {th }}$ graders, two people showed interest in this specialty, but refused to enroll in the group for its preparation.

At the second stage of the study, a special extended lecture was prepared for students of these groups: "The Importance of Epidemiology and Hygiene for Preserving Public Health in Their Historical and Perspective Aspect", during which two major specialists in the field of medical and preventive medicine addressed the students of these groups.

Then a special review lecture was given, in which the main emphasis was placed on the issues of infectious epidemiology. The lecture gave the students the idea of the contents of the work of the epidemiologist, showed them that the development of world civilizations was associated with various epidemics that carried away a large percentage of the population. The most striking examples of deaths from the devastating epidemics of typhoid, smallpox, plague and other diseases of the Middle Ages were given. In particular, the students were given an example of a plague epidemic 
called "black death" in Europe of the 14th century, which claimed the lives of a quarter of the population - 25 million people.

Besides, the students learned about such great scientists and discoverers in the field of microbiology, virology and immunology as L. Pasteur, R. Koch, I.I. Mechnikov, P. Erlich, D.I. Ivanovsky, N.F. Gamaley and many other scientists who have greatly enriched epidemiology by making a revolution in medicine as a whole, which defeated the most dangerous infections causing epidemics[17]. The students were told that the Nobel Prize is considered to be the highest rating in the development of science. More than ten owners of this award in the field of epidemiology were listed, and our compatriot I.I. Mechnikov among them [18].

The speakers indicated that persistent efforts of domestic epidemiologists have been eliminated such diseases as smallpox, plague, typhoid, cholera, malaria and others in Russia. The number of patients with diphtheria, trachoma, and typhoid fever sharply decreased. It was pointed out that today anti-epidemic work should be continued, due to the fact that in some countries neighboring Russia there are cases of outbreaks of acute infections among the population, including smallpox, which can easily penetrate the territory of our state. Along with the sanitary protection of the borders of the Russian Federation, vaccination is necessary, which remains the main measure to combat these diseases.

Modern epidemiology faces a significant number of scientific problems. We observe that more and more previously unknown infections are appearing, some of which were listed in the lecture. It was noted that herpes, cytomegalovirus infection, etc. are of growing importance in human pathology. The lecture focused on acquired immunodeficiency syndrome (AIDS) caused by the human immunodeficiency virus (HIV). The students were told that the number of infected people in the world is more than 40 million and 2 million people worldwide die of AIDS every year. Undoubtedly, the fight against previously known numerous diseases is of great importance. At the present stage, it is generally recognized that for certain diseases that were previously considered non-infectious, the etiology is represented by various microorganisms or viruses, for example, various types of cancer, acute and chronic gastritis and peptic ulcer of the stomach, intestine, etc.

Despite the tremendous achievements in the field of epidemiology and hygiene, we face great challenges in solving the problems mentioned above. The lecture presented the following WHO data: 2 billion people suffer from infectious diseases annually. Thorough epidemiological analysis has shown that among all human diseases about $60-70 \%$ are diseases associated with infectious agents. The economic damage from various epidemics is huge and causes irreparable damage to public health. For example, in the United States alone, the economic damage from influenza is about $\$ 5$ billion a year, which best proves the importance of developing epidemiology.

The epidemiologist is a respected and necessary profession in our country. It requires deep knowledge, moral responsibility and human courage, since such a specialist will have to work in the midst of epidemic and contact dangerous infections. The experience of famous epidemiologists demonstrates such risks. For example, in order to prove the truth, our epidemiology doctors performed dangerous experiments on themselves: O.O. Mogutovsky carried out the self-infection experiment in order to 
study the transmission mechanism of relapsing fever and typhus; S.D. Samoilovich set experiments on himself to prove the presence of immunity after the disease.

Based on the information about the significance and role of the epidemiologist and hygienist in the world and in modern Russia the speaker drew a conclusion: while the medical practitioner treats individual patients, the lives and health of tens and even hundreds of thousands of people depend on the actions of the epidemiologist and hygienist. Those lives can be saved by the timely detection of the causative agent of a possible epidemic, the introduction of appropriate quarantine measures and the required vaccinations, as well as by taking several other necessary measures. Unlimited possibilities of solving the mentioned urgent scientific problems are open for such specialists.

After the lecture Gennady Onishchenko, an epidemiologist, the former Chief Sanitary Doctor of the Russian Federation, the Head of Federal Service for Supervision in the Field of Protection of Consumer Rights and Human Well-being, Doctor of Medical Sciences, Academician of the Russian Academy of Sciences, currently the first deputy chairman of the State Duma Committee on Education and Science; and Yuri Nesvizhsky, Doctor of Medical Sciences, Academician of the Russian Medical and Technical Academy, Dean of Prevention Medicine Faculty of Sechenov University; addressed to the students of newly organized groups and spoke about the history of the development of epidemiology and hygiene in our country, the importance of preventive medical care specialists in modern society, the development prospects of specialties of this area and the conditions of training, as well as the prospects of employment of such specialists. During the presentation, these scientists actively involved the students in the discussion, asked and answered questions. The audience got acquainted with the history of epidemiology and hygiene in our country, starting with the first steps of vaccinating the population. They learned about the influence of this direction on the life of the state and on the quality and life expectancy of the population. The speakers emphasized the courageous and dedicated work of epidemiologists and scientists in this direction, whose efforts eliminated acutely infectious diseases of plague, cholera, smallpox and others causing epidemics, thus preventing huge economic damage to the state. It was emphasized that the state, within the framework of the presidential decree, devotes serious resources to maintaining health and increasing life expectancy. The issues of biological wars and the significance of epidemiologists for their prevention were discussed as well. In the conclusion of their speeches, the speakers emphasized that the specialties of the epidemiologist and hygienist are important and necessary in our country. A good evidence of this fact is the demand and the number of vacancies for such specialists on the Internet even now.

Since the information concerned the students' vital interests - their choice of future profession- they were very active, asked the lecturers questions, and after the end of the presentation they continued to actively discuss this topic among themselves.

Having listened to the speeches of Gennady Grigorievich Onishchenko and Yuri Vladimirovich Nesvizhsky, the students were asked to enroll in the newly created groups (both in the tenth and eleventh grades each group should contain fifteen people) to prepare for entering Sechenov University with a goal of graduating it with a degree in epidemiology. 
18 students from the experimental group of the eleventh-graders expressed a desire to study in the newly created group to prepare for university admission to the specialty of Preventive Medicine with qualifications "hygienist" and "epidemiologist". In addition, $2110^{\text {th }}$-graders enrolled in the groups. Since the number of applicants was bigger than it was necessary, we had to make a selection based on their academic performance.

Having obtained a good result, using the methods of directed interest formation and professional orientation to the profession of an epidemiologist and hygienist among students of biomedical classes in September 2019, we offered to replicate the project in the cadet classes of the city of Moscow. As a result, cadet classes focused on the state civil service in the field of consumer protection and human well-being were organized in Moscow schools. The students of these classes were offered the following events:

- A master-class "Profession in the field of sanitary and epidemiological welfare. Features of work».

- A practical lesson on the topic "Basic ideas about modern approaches to the study and assessment of the state of health, morbidity, physical and mental state of the population".

- Business games "Hygiene as a science. History of hygiene. The concept of "Military hygiene" and "Hygiene of medical institutions".

\section{Conclusion}

The study showed the effectiveness and efficiency of the created method of the directed formation of motivation and professional orientation of high school students to certain medical specialties, depending on the needs of practical health care.

The experience of developing and implementing methods for the directed formation of motivation and professional orientation of high school students to certain medical specialties, presented in this article, may be useful in creating innovative systems of secondary general education of various profiles. It is economical, since it does not require large expenses on its organization and conduct. Mastering this method does not require long and complicated training of experts and students.

\section{$5 \quad$ References}

[1] Kostyukov, N.N. (2009) Some issues of improving the training of doctors in modern conditions. Part 2. Psychological and pedagogical conditions for the formation of educational and professional activities. Moscow: Ikar,.204.

[2] Kostyukov, N. N., Molodozhnikova N. M. (2016) Psychological and pedagogical problems of the formation of motivation for learning/ Psychology. Historical and critical reviews and modern research, 2,49-65.

[3] Kostyukov, N.N., Molodozhnikova N.M, Fokina M.A. (2016) Formation of motivation (interest) in the subject and process of activity. Saarbrucken: LAP Lambert, 67. 
[4] Kostyukov, N.N., Fokina M.A., Molodozhnikova N.M. (2018) Psychological and pedagogical problems of motivation formation for the study of academic disciplines. Medical Education and University Science,1 (11), 29 - 35.

[5] Bozovic, L. I. (2008) Personality and its formation in childhood. - SPb. Peter, 398.

[6] Kon, I.S. (1982) Psychology of high school student. Moscow: Education, 207.

[7] Sook, I.S. (1984) The doctor as a person. Moscow: Medicine, 64.

[8] Biryukova, N.V., Litvinova T.M., Nesterova O.V. (2018) Integrative model of preuniversity education implemented at Sechenovskiy University. Problems of the formation of education, 6, 159 - 178.

[9] Elkonin, D. B. (1989) Selected psychological works. Moscow:Pedagogy, 555.

[10] Elkonin, D. B. (2006) Child psychology. Moscow: Academy, 384.

[11] Brother, B.S. (1986) Moral consciousness of personality. Moscow. 68.

[12] Bestuzhev-Lada, I.V. (1988) To the school of the XXI century. The thoughts of a sociologist. Moscow: Pedagogy, 128.

[13] Krylov, N.I. (1973) Professional orientation of working youth as a problem of moral education. Psychology Issues, 1, 68-74.

[14] Volkova, E.I. (2018) Motivation for choosing a profession. Innovative development of vocational education, 3 (19), 54-62.

[15] Litvinova, T.M. Kozar M.V. (2017) Organization of specialized biomedical classes at Sechenov University in general education organizations. Medical Education and University Science, 2 (10), 26 - 30.

[16] Molodozhnikova, N. M. Biryukova N. V., Galustyan O.V., Lazareva Ju. B., Stroiteleva N. N. (2020) Formation of Professional Orientation of High School Students to Medical Profession by Using ICT Tools. International Journal of Emerging Technologies in Learning, 15 (№1), 231-239. https://doi.org/10.3991/ijet.v15i01.11423

[17] Galustyan, O.V., Kirik V.A., Mazáčová N.(2019) Partnership of University and Schools Within the Preparation of Future Teachers. International Journal of Emerging Technologies in Learning, 14(17), 153-161. https://doi.org/10.3991/ijet.v14i17.10829

[18] Genç, Z., Masalimova, A. R., Platonova R. I., Sizova, Z. M., Popova, O. V. (2019) Analysis of Documents Published in Scopus Database on Special Education Learning Through Mobile Learning: A Content Analysis. International Journal of Emerging Technologies in Learning, 14 (22), 192-203. https://doi.org/10.3991/ijet.v14i22.11732

\section{Authors}

Natalya V. Biryukova is Director of the Resource Center "Medical Sechenov PreUniversity" of I.M. Sechenov First Moscow State Medical University (Sechenov University), Moscow, Russia. Email: N.V.Birukova@mail.ru

Natalia M. Molodozhnikova is Associate Professor of the Department of Biology and General Genetics of I.M. Sechenov First Moscow State Medical University (Sechenov University), Moscow, Russia.

Article submitted 2020-02-27. Resubmitted 2020-03-31. Final acceptance 2020-04-01. Final version published as submitted by the authors. 